\title{
Article
}

\section{Profile of high-performing college soccer teams: An exploratory multi-level analysis}

Filho, Edson, Gershgoren, Lael, Basevitch, Itay and Tenenbaum, Gershon

Available at http://clok.uclan.ac.uk/14056/

Filho, Edson ORCID: 0000-0002-8548-4651, Gershgoren, Lael, Basevitch, Itay and Tenenbaum, Gershon (2014) Profile of high-performing college soccer teams: An exploratory multi-level analysis. Psychology of Sport and Exercise, 15 (5). pp. 559-568. ISSN 1469-0292

It is advisable to refer to the publisher's version if you intend to cite from the work.

For more information about UCLan's research in this area go to

http://www.uclan.ac.uk/researchgroups/ and search for < name of research Group>.

For information about Research generally at UCLan please go to http://www.uclan.ac.uk/research/

All outputs in CLoK are protected by Intellectual Property Rights law, including Copyright law. Copyright, IPR and Moral Rights for the works on this site are retained by the individual authors and/or other copyright owners. Terms and conditions for use of this material are defined in the policies page.

\section{CLoK}

Central Lancashire online Knowledge www.clok.uclan.ac.uk

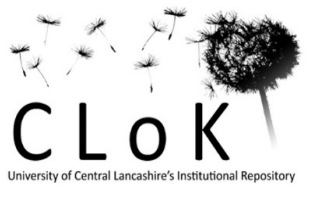




\section{multi-level analysis}

Edson Filho ${ }^{\mathrm{a}}$, Lael Gershgoren ${ }^{\mathrm{b}}$, Itay Basevitch ${ }^{\mathrm{c}}$ and Gershon Tenenbaum ${ }^{\mathrm{c}}$

a Behavioral Imaging and Neural Dynamics Center, University of Chieti-Pescara, Italy

${ }^{\mathrm{b}}$ Zinman College of Physical Education and Sport Sciences, Wingate Institute \& Ohalo

11 Academic College of Education and Sport

${ }^{\mathrm{c}}$ Department of Educational Psychology and Learning Systems, Florida State University, United States

Corresponding Author:

Edson Filho

Behavioral Imaging and Neural Dynamics Center

University of Chieti-Pescara

Via dei Vestini, 33 - 66013, Chieti, Italy

Email: soares_medeiros@yahoo.com.br

Phone: +39 333.304.5650 / +49 0176.3514.6564 
Abstract

Purpose: To determine the profile of high-performing college soccer teams through the use of

37 exploratory hierarchical linear modeling (HLM) based on a socio-cognitive approach.

Design and Measures: A correlational design was employed in this study. The sample consisted of 340 college soccer players of both genders (178 female and 162 male), representing 17 different teams (8 female and 9 male) ranked in the top-32 of the National Association of Intercollegiate Athletics (NAIA). Numerous demographic and soccer-related variables represented level-1 in the HLM model. Group Environment Questionnaire and Team Assessment Diagnostic Measure were entered as level-2 variables, representing cohesion and team mental models, respectively. Perceived performance potential (PPP) served as the dependent variable. 45 Objective performance scores were correlated with PPP, attesting a moderate to high-level of 46 criterion related validity $(r=.78)$.

47 Results: The final model suggested that: (1) International athletes perceive their performance lower than others, (2) different field positions share different covariance coefficients with PPP, 49 and (3) perception of social cohesion from a group, rather than individual, standpoint is 50 positively associated with perceptions of team performance.

51 Conclusions: High performing teams have clearly defined task-related and team-related goals.

52 Accordingly, social rather than task related factors may represent a competitive edge, further 53 energizing the interactions and performance of top-ranked teams. International athletes perceive 54 team performance lower than locals, perhaps due to differences in preferred game-style and 55 acculturation experiences. Players from different field positions (i.e., goalkeepers, defensive, and 56 offensive players) relate differently to team performance in college soccer.

57 Keywords: Team expertise; Team Mental Models; Cohesion; HLM; Soccer. 


\section{Profile of High-Performing College Soccer Teams: An Exploratory Multi-Level Analysis}

There is a general agreement that people achieve more when working in synchrony towards a shared goal: "the whole is greater than the sum of its parts." In this regard, team expertise is a cross-domain research topic and numerous scholars seek to understand how successful sport teams, airline pilots, music orchestras, and even global diplomats evolve implicit and explicit coordination mechanisms (Salas, Rosen, Burke, Goodwin, \& Fiore, 2006). Nonetheless, capturing team expertise is challenging because both individual and team-level factors influence the development of high-performing teams (Eccles \& Tenenbaum, 2004). In a nutshell, previous research suggests that team expertise is about finding the "ideal mix" of individuals” backgrounds and skills, while promoting team values and coordination (i.e., synchronized action and effort among teammates) (see Gratton \& Erickson, 2007). Therefore, we advanced an exploratory hierarchical linear model considering both individual and team-level factors related to team performance. Specifically, we assessed the influence of soccer players’ personal characteristics on team performance. We subscribed to a socio-cognitive approach based on the notion that teammates’ social dynamics (e.g., cohesion) influence individuals beliefs and cognitions (e.g., performance expectations), which in turn influence team members’ social dynamics (Eccles \& Tenenbaum, 2014). To this extent, social cognition has been defined as “information processing in social setting” (Frith, 2008, p. 2033) and considered the result of how social stimuli influence perceptions of group processes. Moreover, with numerous frameworks to choose from (e.g., collective-efficacy, leadership), we opted to limit the scope of our inquiry to the notions of team cohesion and team mental models. From a theoretical standpoint, cohesion has been associated with the development of team processes such as team mental models (Carron \& Hausenblas, 1998), while found to be moderated by a number of personal factors (see Carron, 
81 Colman, Wheeler, \& Stevens, 2002) considered in the model tested herein. Finally, both

82 cohesion and team mental models have been linked to team performance and expertise in sports

83 (Carron, Eys, \& Burke, 2007; Eccles \& Tenenbaum, 2004).

\section{Team Cohesion} 101 variable.

Team cohesion is defined as "a dynamic process that is reflected in the tendency of a group to stick together and remain untied in the pursuit of its instrumental objectives and/or for the satisfaction of member affective needs” (Carron, Brawley, \& Widmeyer, 1998, p. 213). Task and social cohesion are the two sub-dimensions underlying the overarching notion of team cohesion. Task cohesion refers to the degree that members of a team bond to accomplish a task, thus remaining united to achieve shared performance related goals. Social cohesion pertains to the notion of teammates bonding for social reasons, thus reflecting the extent that members of a team like to interact and enjoy each other’s company (Carron, Eys, \& Burke, 2007; Carron, Widmeyer, \& Brawley, 1985; Widmeyer, Brawley, \& Carron, 1985). Based upon the notions of task and social cohesion, Carron et al. (1985) proposed the Conceptual Model of Group Cohesion for Sport. This framework considers each athlete's perceptions about his/her particular social and task attraction to the team ("I, my, or me” perceptions). Furthermore, this framework considers athletes’ perceptions about “team unity” (“us, our, or we” perceptions), as related to "the similarity, closeness, and bonding, within the team as a whole around the group task" (Widmeyer et al., 1985, p. 17). In the present study, “I” beliefs were entered as level-1 factors, and "us" beliefs were treated as level-2 factors, with performance serving as the dependent

It is important to note that performance has also been hypothesized to influence team cohesion and vice-versa (Carron et al., 2002). In fact, the relationship between cohesion and 
104 105 106

107 108 109 110 111

performance has been extensively studied across domains, and two meta-analytic reviews have summarized the magnitude of the cohesion-performance relationship (Carron et al., 2002; Mullen \& Copper, 1994). Mullen and Copper’s meta-analysis (1994) included 49 studies from general, military, and sport psychology. Results revealed a significant, positive, and small effect size $(d)$ for the cohesion-performance relationship $(d=.25, p<.01)$. In another meta-analytic review, Carron et al. (2002) found a large effect size for the cohesion-performance relationship in sports. Carron et al. also reported a strong relationship between performance and social $(d=$ $.70)$ and task cohesion. $(d=.61)$.

Research based on Carron et al.'s (1985) Conceptual Model of Group Cohesion for Sport has also revealed that team members' attributes may serve as moderators of the cohesionperformance relationship (Carron et al., 2002; Carron et al., 2007). To this extent, Carron and Hausenblas (1998) have long noted that team member attributes influence group structure which in turn impact the cohesion-performance relationship. Based on this rationale, we focused on statistically modelling the influence of team members’ attributes (individual characteristics, level-1 variables) on team performance. In particular, we examined the influence of both team members' demographic and role attributes on team performance. Pertaining to team members' demographic attributes, we assessed athlete gender and nationality. This is consistent with previous research suggesting that the cohesion-performance relationship differ among female and male teams, and that cultural issues may impact group cohesion in sports (Popp, Hums, \& Greenwell, 2010). Furthermore, we used class status (i.e., freshman, sophomore, junior, senior) as an indicator of athletic experience, another factor influencing performance in college sports 125 (Watt \& Moore, 2001). 

soccer charteristics (i.e., field position, laterality, starter status) on team performance. In this

128 regard, field position has been linked to the development of group processes and performance in 129 team sports (Filho, Gershgoren, Basevitch, Schinke, \& Tenenbaum, in press). For instance, 130 midfielders occupy centralized positions where the access to information is maximized, whereas 131 other players (goalkeepers, defenders and offensive players) have unique assignments during 132 competition (Di Salvo et al., 2007). Also noteworthy, laterality has been proposed as a factor 133 linked to performance in team sports (Carey et al., 2001). Specifically, Carey et al. noted that 134 left-footed players are rare and thus may have advantages because (a) defenders are most 135 practiced against right foot opponents, and (b) left-footed plays are more likely to access visuo136 spatial creativity networks in the right cerebral hemisphere. Finally, athletes’ starter status have

137 been found to influence team dynamics, with higher status athletes (e.g., starters) showing 138 greater perceptions of satisfaction and cohesion than lower status athletes (e.g., substitutes) (see 139 Jeffery-Tosoni, Eys, Schinke, \& Lewko, 2011). Previous research on expert performance in 140 soccer revealed that highly skilled athletes tend to possess greater awareness of their 141 performance outcomes than their less skilled counterparts (Basevitch, Ward, Ericsson, Ehrlinger, 142 \& Filho, 2010). Accordingly, given starters are (in principle) the more skilled players, it is 143 plausible that they evaluate performance differently than substitutes. In all, we examined the 144 relationship among athletes’ personal factors (i.e., starter status, laterality, field position and 145 college experience), perceptions of cohesion (social and task), and team performance. Moreover, 146 we were also interested in testing the influence of team mental models on team performance.

\section{Team Mental Models}


The term “Team Mental Models” (TMM) has been used to denote research on team cognition because it clearly conveys that "the locus of interest is on team functioning, and it is stated broadly enough to encompass both similarity and accuracy properties” (Mohammed, Ferzandi, \& Hamilton, 2010, p. 4). More specifically, TMM is defined as "the collective task and team relevant knowledge that team members bring to a situation” (Cooke, Salas, CannonBowers, \& Stout, 2000, p. 153). Accordingly, TMM are thought to enhance team performance through the development of (a) coordination mechanisms, and (b) task-specific and team related knowledge (see Eccles \& Tenenbaum, 2004; Ward \& Eccles, 2006).

Team coordination was recently defined as “the process of arranging team members’ actions so that, when they are combined, they are in suitable relation for the most effective result” (Eccles \& Tran, 2012, p. 32). Noteworthy, the importance of explicit and implicit coordination mechanisms has been noted by scholars from various domains (Eccles \& Tenenbaum 2004; Entin \& Serfaty, 1999; Mohammed et al., 2012). Explicit coordination refers to verbal communication used to facilitate division of labor among teammates, whereas implicit coordination pertains to the ability of teammates to articulate team level actions without the need for verbal communication (Ward \& Eccles, 2006). To this extent, Entin and Serfaty (1999) noticed that naval teams adapt to highly stressful situations by creating implicit coordination mechanisms.

When developing team coordination, one should also keep in mind that team actions must be synchronized in function, time, and space. In this regard, Eccles (2010) has proposed action type, action timing and action location as the three important antecedents of team coordination. Action type pertains to one's expectation or anticipation of an upcoming action made by a teammate. The accuracy of this anticipatory mechanism is crucial to one's ability to prepare 
171 him/herself to future events. Action timing relates to the ability of team members to correctly

172 align their actions "on the fly," thus avoiding "too early” or "too late” responses. Lastly, Eccles

173 highlighted that optimal coordination is environmentally situated at a specific space. Hence, it is

174 important that teammates anticipate what is about to happen "where” (space).

175 Team expertise has also been linked to the similarity and accuracy of task-specific and 176 team-related knowledge (Cooke et al., 2000). Task-related knowledge is task-specific and

177 idiosyncratically distributed among team members. Team-related knowledge refers to

178 "knowledge held by teammates and their collective understanding of the current situation"

179 (Cooke et al., 2000, p. 154), and involves communal understanding of team procedures, 180 strategies, and contingency plans. According to Mohammed et al. (2010), task-related knowledge 181 specifies “what needs to be accomplished” by each team member, whereas team-related 182 knowledge refers to work coordination (i.e., "how work needs to be accomplished”). Of note, 183 both task-specific and team related knowledge have been found to be associated with team 184 performance in open skill motor tasks (Mathieu, Heffner, Goodwin, Salas, \& Cannon-Bowers 185 (2000).

The importance of team and task-related knowledge is particularly evident in soccer

187 matches. For instance, goalkeepers possess highly task-specific knowledge, which is also 188 essential to overall team performance (Ward \& Eccles, 2006). On the other hand, team 189 performance is also dependent on the tactical knowledge of all players who enter the pitch. Thus, 190 soccer players must hold common knowledge (i.e., team-related knowledge) regarding their team 191 strategies (e.g., team formation such as 1-4-3-3 or 1-3-5-2). It is also important to note that task192 specific and team-related knowledge are developed over time, and especially in moments of 193 action (i.e., during practice and training) (see Eccles \& Tenenbaum, 2004). Accordingly, we 
194 collected data at the end of the competitive cycle, in agreement with the notion that a group of 195 individuals undergo a process of development before evolving task-specific and team-related 196 knowledge. Moreover, we relied on the expert-performance approach, thus only focusing on the 197 performance dynamics (i.e., moderating variables) of highly-ranked soccer teams.

In all, we sought to determine the profile of high-performing college soccer teams through 199 the use of exploratory hierarchical linear modeling (HLM) based on a socio-cognitive approach 200 reflecting the notions of cohesion and TMM. We expected that demographic and soccer related 201 variables would predict perceived performance potential (see Figure 1). This is consistent with 202 the overall notion that individual characteristics (e.g., gender, nationality, field position) 203 moderate perceptions of team outcome (Carron et al., 2007). Furthermore, we expected that (at 204 least) one latent factor representing group perceptions of socio-cognitive factors (i.e., Cohesion 205 and TMM) would add explicative power to subjective accounts of team performance. This is 206 congruent with (1) the theoretical notion that socio-cognitive factors are linked to team expertise 207 (see Eccles \& Tenenbaum, 2004), and (2) methodological guidelines on parsimonious HLM 208 model, in which latent factors must be added on a "one by one” basis (Raudenbush \& Bryk, 209 2002).

Methods

\section{Participants}

Three hundred and forty college soccer players of both genders (178 female $-52.40 \%$; and 213162 male - 47.60\%) representing 17 different teams (8 female and 9 male) affiliated to the 214 National Association of Intercollegiate Athletics (NAIA) agreed to participate in the study. The 21517 teams represented in this study were from nine different states (Alabama, California, Florida, 216 Iowa, Kansas, Kentucky, Michigan, Montana, and Ohio). Participants were 20.38 years old on 
217 average $(S D=2.12)$ and had 14.66 years $(S D=3.92)$ of experience in the sport. On average, the 218 participants had been playing for their respective teams for 2.40 years $(S D=1.11)$. They were 219 predominantly Caucasians (70.60\%) and “other races” (15.20\%). Black/Afro-Americans

220

221

222

223 background. represented $6.60 \%$, and Hispanic/Latinos represented $4.20 \%$ of the total sample size. American Indian/Alaskan Native represented .09\% $(n=3)$. Two Japanese $(n=2)$ and one Korean also participated in this study. Five student athletes (i.e., 1.50\%) chose not to report their ethnic

224

225

226

227

228

229

230 231

232

233

234

235 236 237 238 239

\section{Instrumentation}

Demographic Questionnaire. A detailed demographic form was utilized to collect normative data. Specifically, participants’ age, nationality, ethnicity, starter status (i.e., starter or substitute), field position (i.e., goalkeeper, defender, midfielder, offense), laterality (i.e., right or left footed), years of experience in soccer, and class (i.e., freshman, sophomore, junior, senior) were obtained. This data were deemed important to characterize the study’s sample.

Furthermore, this information was used to estimate the linkage between participants' soccer experience and profile, and perceived team performance.

Group Environment Questionnaire (GEQ; Widmeyer et al., 1985). The GEQ, a conceptually-driven instrument, has been the primary choice of sport psychologists interested in studying cohesion in team sports for the past 25 years (Carron et al., 2002; Carron et al., 2007). Hence, given its theoretical and applied representativeness, the GEQ was chosen as the measurement tool pertaining to cohesion. Specifically, the GEQ is an 18-item measure, with anchors ranging from 1 (i.e., strongly disagree) to 9 (i.e., strongly agree), which measures team cohesion as related to the following four dimensions: (a) Individual Attraction to the GroupSocial (ATG-S; e.g., "Some of my best friends are on this team.”); (b) Individual Attraction to 
240 the Group-Task (ATG-T; e.g., “I like the style of play on this team.”); (c) Group Integration-

241 Social (GI-S; e.g., “Our team would like to spend time together in the off-season.”), and (d)

242 Group Integration Task (GI-T; e.g., “Our team is united in trying to reach its performance

243 goals.”). Of note, ATG-S and ATG-T aim at capturing each athlete's perceptions concerning

244 his/her particular social and task attraction to the team individual. On the other hand, GI-S and

245 GI-T aim at capturing each athlete’s perceptions of the team “as a whole”. Notwithstanding,

246 there is empirical evidence supporting the factorial properties of the instrument, as well as its

247 content, concurrent and predictive validities (Carron et al., 1998). Furthermore, Carron et al.

248 (1998) reported that Cronbach alphas for the four hypothetical dimensions of the GEQ are for the

249 most part satisfactory (i.e., $\alpha \geq .70$ ). In the present study, items were reversed when needed and

250 Cronbach alpha coefficient ranged from .56 to .75. The entire scale’s alpha reliability was .85.

Team Assessment Diagnostic Measure (TADM; Johnson et al., 2007). The TADM was

252 designed to measure sharedness of team-related knowledge. This 15-item questionnaire, with

253 anchors ranging from 1 (i.e., strongly disagree) to 5 (i.e., strongly agree), reflects the following

254 five factors: (a) General Task and Team Knowledge (GTTK; e.g., "My team usually discusses

255 our goals and attains the agreement of each other.”); (b) General Task and Communication Skills

256 (GTC; e.g., "My team communicates with each other while performing our task.”); (c) Attitudes

257 towards Group Teammates and Task (GTT; e.g., “My team takes pride in our work.”), (d) Team

258 Dynamics and Interactions (GTI; e.g., "My team solves problems that occur while doing our

259 task.”), and (e) Team Resources and Working Environment (TRWE; e.g., "My team knows the

260 environmental constraints when we perform our work.”). These factors were found to have

261 satisfactory reliability coefficients (i.e., $\alpha \geq .75$ ) and to account for $82 \%$ of the variance on 
262 sharedness of team-related knowledge (Johnson et al., 2007). In this study, Cronbach alpha 263 coefficients ranged from .74 to .84 and the entire scale’s alpha reliability was .91.

264 Team Outcome Questionnaire (TOQ; see Coleman, 2011; Appendix H). The TOQ

265 consists of 9 items that describe goals related to team skills, strategy, effort, competitive

266 outcomes, and fitness. These areas were selected based on a content analysis of team

267 performance expectations conducted by Brawley, Carron and Widmeyer (1992). The TOQ uses a

268 Likert-type scale ranging from 0 (i.e., low expectations) to 4 (i.e., high expectations) to measure

269 perceived performance potential (PPP) in team sports. An exploratory factor analysis resulted in

270 a unidimensional scale with homogeneous items accounting for 54.71\% of the variability on

271 team performance expectation. Internal consistency across all items was satisfactory resulting in

272 a Cronbach alpha coefficient of .89.

The TOQ was utilized to assess perceived performance potential (PPP), which is a

274 subjective account of a team's performance from the perspective of a team member. In fact, PPP

275 is a cross-domain topic pertaining to the performance of working teams in business, sports, and

276 the military (Stumpf, Doh, \& Tymon, 2010). Furthermore, the notion of PPP is also congruent

277 with a current probabilistic, rather than deterministic, view of performance in sports (Kamata,

278 Tenenbaum, \& Hanin, 2002). In particular, subjective reports may better represent an athletes’

279 performance experience as purely objective scores may misrepresent referee mistakes, an

280 outstanding performance from an opposing individual or team, among other situational and

281 environmental constraints (e.g., bad weather, injury) (see Chelladurai, 2007). Moreover, a

282 subjective account of performance was deemed methodologically appropriate as cohesion and

283 TMM scores represented self-perceptions rather than objective values. Notwithstanding, team’s

284 objective performance (mean points as measured by the number of wins, ties and losses) were 
correlated with TOQ scores, resulting in a .78 coefficient, which thereby suggest a moderate to high degree of criterion-related validity regarding the notion of PPP.

\section{Procedures}

Institutional Review Board approval was obtained prior to the commencement of this study. Participants were educated about the overarching theme of the study and signed an informed consent form. Data were collected during the NAIA finals, a single-elimination tournament involving the top 32 teams in this college division. Specifically, NAIA college soccer coaches were contacted, and upon agreement, a time was scheduled to meet their respective players. The athletes were informed about the study rationale, and upon voluntary agreement, were asked to sign the written informed consent. Participants received a package of questionnaires (i.e., GEQ, TADM, and the demographic form), presented in a randomized order to control for learning and motivational effects. Data were collected one day before a decisive playoff game at the national tournament. Specifically, data collection occurred in a quiet environment (meeting rooms) and coaches were not present during data collection. Participants had played a median of 20 matches $(M=19.7, S D=1.39)$ over the season prior to the study, consistent with the notion that a group of individuals undergo a process of development before becoming a “team” (Eccles \& Tenenbaum, 2004).

\section{Data Analysis}

A two-level hierarchical linear model (HLM) was tested with individual variables representing level-1 and team-level constructs representing level-2. Figure 1 is a schematic descriptive summary as well as a graphic representation of all variables considered in the HLM analysis. The dependent variable PPP was transformed into percentage scores to allow for ease of interpretation of the estimated regression coefficients. Furthermore, with the exception of 
308 ATG-T and ATG-S scores, all level-1 variables were dummy coded as follow: (a) gender $(0=$ 309 female / 1 = male); (b) nationality status ( 0 = local citizen / 1 = international); (c) laterality $(0=$ 310 left footed $/ 1$ = right footed); (d) starter status ( 0 = substitute $/ 1$ = starter $)$; (e) class status with 311 its four independent entries as freshman, sophomore, junior, senior ( 0 = no / 1 = yes); and (f) 312 field position with its four independent clusters being goalkeeper, defender, midfielder, and 313 offensive player $(0=$ no $/ 1=$ yes $)$. As such, the dummy coded variables were treated as fixed

314 effects, whereas ATG-T and ATG-S scores (ranging from 1 to 9) were conceptualized as random 315 effects in the tested model. Furthermore, level-1 variables were treated as raw, non-centered 316 scores given that there was (1) an interest in estimating the unique contribution of each level-1

317 predictor, and (2) no occasion in which a value of zero represented either an undesirable or 318 unreasonable score. Level-2 variables were treated as random effect and consisted of all TADM 319 subscales (i.e., GTTK, GTC, GTT, GTI and TRWE) and the group level scales from the GEQ 320 measure (i.e., GI-S and GI-T). Due to space limitations, only the unconditional and the final model were defined in the text. Prior to the model test, descriptive and psychometric analyses 322 were computed for all TADM and GEQ subscales.

\section{Results}

\section{Demographics}

Prior to the regression analysis, the frequency distribution of the dummy coded variable was computed. All variables exceeded the minimum 5\% response rate suggested as a guideline

327 for survey, regression based studies in the human and social sciences (Creswell, 2008). The 328 participants were primarily in their junior (i.e., 33.2\%) and freshman (i.e., 29.7\%) years.

329 Sophomores and seniors represented $16.9 \%$ and $19.8 \%$ of the total sample size, respectively. The majority of players were right-footed (i.e., 72.3\%) and "starters” (i.e., 61.3\%), whereas the 
331 remaining $27.7 \%$ were left-footed with $38.7 \%$ identifying themselves as "substitutes.”

332 Goalkeepers constituted $11.1 \%$ of the total sample size; defenders, midfielders and offensive

333 players represented 30.1\%, 36.1\% and 22.7\%, respectively. Overall, $66.8 \%$ of the total sample

334 size was American citizens, whereas the remaining 33.2\% identified as international student335 athletes.

\section{Psychometrics}

Reliability Analyses. Means, standard deviation, statistical range and estimates of internal consistency reliability of the model's variables are presented in Table 1. Means represent aggregated scores in accordance with HLM standard procedures. Most internal consistency coefficients were above the minimal cut-off value of .70. The exceptions were the ATG-S and ATG-T subscales with values of .56 and .63, respectively. Given that this high measurement

342 error could not be corrected, as item analysis did not warrant the removal of any item, these 343 subscales scales were not included in the level-1 HLM model as initially proposed. Indeed, 344 scholars have suggested psychometrical revisions of the GEQ, particularly advocating for either 345 (1) a simpler (i.e., with less sub-dimensions) factorial solution (Carless \& De Paola, 2000), or (2) 346 a modified questionnaire containing only positively worded items (Eys, Carron, Bray, \& 347 Brawley, 2007).

Correlational Analyses. Correlation coefficients are presented in Table 2. The values 349 across the GEQ subscales (i.e., ATG-T, ATG-S, GI-T, and GI-S) ranged from .23 to .51, 350 suggesting that task and social cohesion shared variance but are still relatively independent constructs. Correlation coefficients involving the TADM subscales (i.e., GTTK; GTC; GTT;

352 TDI; TRWE) were between.48 and .76, indicating a higher degree of convergent validity among 353 the team mental model factors measured in this study. Noteworthy, given that level-2 variables 
354 must be entered on a “one by one” basis in HLM models, any potential multicolinearity threat $355(r>.70)$ could be identified and controlled for upon model testing. Moreover, coefficients 356 among the GEQ, TADM, and TOQ composite scores ranged from .25 to .55, hence suggesting a 357 degree of convergent validity, while also signaling a degree of divergent validity, and thus 358 reduced multicolinearity threats. As noticed before, TOQ scores and objective performance 359 scores showed a correlation of .78, thereby indicating a moderate to high degree of criterion360 related validity.

\section{Unconditional Model}

Once the psychometric properties of each scale were found to be reliable, we tested the

363 initial unconditional model (defined below) in which no independent variables were used.

364 Results indicated significant variation in the means of PPP across soccer teams. Specifically, the 365 intra-class correlation for this model indicated that 9.5\% of the PPP was due to between-groups 366 differences. Hence, a hierarchical solution was warranted as outcome scores (slopes) differed by 367 team membership. The grand mean estimate was $\gamma_{00}=82.22(p<.01)$, and represents the average 368 value of PPP across soccer teams. Furthermore, the value reliability of the sample was 369 appropriated (i.e., < .70), indicating that $86.5 \%$ of the variation in the PPP means reflect true 370 variation between soccer teams. The deviance for this model was of $\chi^{2}(2)=2662.46$, thus 371 establishing an initial goodness-of-fit index for subsequent model comparison.

372 Level-1 Model

$373 \quad P P P j=\beta_{0 j}+r_{i j}$,

$374 \quad$ Level-2 Model

$375 \quad \beta_{0 j}=\gamma_{00}+u_{0 j}$

376 where, 
$377 \beta_{0 \mathrm{j}}$ is the intercept. andr $_{\mathrm{ij}}$ is the residual

$378 \gamma_{00}$ is the grand mean outcome (PPP) in the population

$379 \mathrm{u}_{0 \mathrm{j}}$ is a random effect for soccer team $\mathrm{j}$

380

381

382

383

384

385

386

387

388

389

390

\section{Level-1 Modeling}

Model 1A. Coefficients, standard error, and $p$-value for all tested variables are given in in Table 3. Noteworthy, this model included all individual level-1 variables (see Figure 1) with the exception of ATG-T and ATG-S, which were excluded due to high measurement error. The value reliability of the sample increased to $88.4 \%$ and deviance decreased to $\chi^{2}(2)=2590.16$ when compared to the unconditional model. Nonetheless, this model was not considered final as the variables "gender," "laterality,” “starter status,” and none of the classes' status entries (i.e., freshman, sophomore, junior, senior) were significant. Furthermore, the dummy coded entry “midfielders” did not yield significant results, and thus was also excluded from the next tested model.

Model 1B. Results for all tested variables are given in Table 4. All independent variables included in this model (i.e., nationality, goalkeeper, defender, offensive player) were found to be significant $(p<.05)$. Specifically, international players $\left(\gamma_{10}=-4.09, p=.02\right)$ were found to have lower perceptions of team performance than their non-international counterparts. Predicted scores on PPP were also different depending on one's field position, with the exception of “midfielders”. Specifically, estimated PPP coefficients for goalkeepers $\left(\gamma_{20}=4.50, p=.04\right)$, defensive $\left(\gamma_{30}=5.23, p<.01\right)$ and offensive $\left(\gamma_{40}=5.38, p<.01\right)$ players showed slightly different magnitudes. Noteworthy, the values for the sample reliability (i.e., 88.6\%) and deviance $[\chi 2(2)=2630.16]$ were indicative of a better model fit when compared to the unconditional model. Accordingly, the next step involved the consideration of group-level variables. 
400

401

402 are defined below.

403

404

405

406

$407 \quad \beta_{1 j}=\gamma_{10}$

$408 \quad \beta_{2 j}=\gamma_{20}$

$409 \quad \beta_{3 j}=\gamma_{30}$

410

$411 \beta_{0 j}$ : Mean for PPP for group j considering GI-S scores, and controlling for international,

412 goalkeeper, defensive player, and offensive player status ( 0 or 1 , dummy variables).

$413 \beta_{1 j}$ : The predicted change in PPP when "international" is equal to one in soccer team $\mathrm{j}$,

414 controlling for all other independent variables.

$415 \beta_{1 j}$ : The predicted change in PPP when "goalkeeper" is equal to one in soccer team $\mathrm{j}$,

416 controlling for all other independent variables.

$417 \beta_{2 j}$ : The predicted change in PPP when "defensive player" is equal to one in soccer team $\mathrm{j}$,

418 controlling for all other independent variables.

$419 \beta_{3 j}$ : The predicted change in PPP when "offensive player" is equal to one in soccer team $\mathrm{j}$,

420 controlling for all other independent variables.

$421 \quad r_{i j}$ : It represents the deviations of PPP from its predicted value for individual $\mathrm{i}$ in group $\mathrm{j}$. 

priori exploratory analysis was conducted to determine which level-2 variables must be included 424 in the model on a "one by one” basis. This analysis revealed that including TDI, GI-T and GI-S 425 would produce similar contributions to a potential final model. The inclusion of TDI and GI-T 426 into the regression matrix did not yield significant intercepts, and thus these terms were excluded 427 from further analysis. However, the inclusion of GI-S yielded a significant coefficient $\left(\gamma_{00}=\right.$ 428 54.26, $p<.01$ ) while also representing an overall improvement to the previously tested Model 2. 429 Specifically, reliability of the sample mean remained high (88.5\%) and deviance scores were 430 lowered to $\chi^{2}(2)=2624.79$. Computation of the pseudo R-square score indicated that this model 431 represented an improvement of 5\% to the unconditional model. Perhaps more importantly, the 432 final model (product of an exploratory analysis and which terms are defined below) made 433 theoretical and applied sense, as athletes" "individual characteristics” such as field position and 434 nationality, as well as teammate’s perception of social cohesion have been proposed as potential 435 moderators of team performance (Carron et al., 2007).

436 In essence, this final model suggested that (1) "being an international player” is 437 negatively associated with PPP scores $\left(\gamma_{10}=-3.93, p=.02\right)$; (2) different field positions share 438 different covariance coefficients with PPP (i.e., goalkeepers $\gamma_{20}=4.61, p=.04$; defensive players $439 \gamma_{30}=5.19, p<.01$; offensive players $\gamma_{40}=5.43, p<.01$ ), with the exception of "midfielders" 440 where no significant effect was found; and (3) perception of social cohesion from a group 441 standpoint (i.e., GI-S aggregated scores) is positively related to PPP $\left(\gamma_{01}=3.88, p<.01\right)$.

442 Therefore, considering the final coefficients estimated for this sample (see Table 5), the lowest 443 “error free” hypothetical PPP value (i.e., 54.21 out of 100) would (a) be given by the equation 444 $P P P=54.26+3.88 *(1)-3.93 *(1)+4.61 *(0)+5.19 *(0)+5.43 *(0)$; and (b) represent an 
445

446

447

448

international midfielder whose team's aggregated GI-S scores is the lowest possible (i.e., 1). The maximum hypothetical PPP score (94.56 out of 100) would (a) be given by the equation PPP $=54.26+3.88 *(9)-3.93 *(1)+4.61 *(0)+5.19 *(0)+5.43 *(1)$; and (b) represent an offensive player whose team's aggregated GI-S perception is the highest possible (i.e., 9).

\section{Discussion}

Few researchers have examined the characteristics and components that predict successful performance of sport teams (Eccles \& Tran, 2012; Raab \& Johnson, 2007).The dynamic nature and complexity of team sports (e.g., coordination, communication, and cohesion) make it difficult to study the relationship among individual and team characteristics, and team performance. Nonetheless, researchers in recent years have attempted to elucidate the components (and relationship among them) that are required to achieve team success and expertise (Eccles \& Tenenbaum, 2004; Fiore et al., 2007). We examined how individual characteristics (i.e., demographic factors and soccer characteristics) and team socio-cognitive factors (i.e., cohesion and team mental models) were related to perceived team performance (i.e., PPP) using a multilevel analysis approach. The findings indicated that individual (i.e., nationality and field position) and team factors (i.e., social cohesion) significantly contributed to the prediction of perceived performance. In the following sections, the predictive value of each individual and team socio-cognitive factor is discussed.

\section{Individual Characteristics}

Gender. Results indicated that gender did not significantly contribute to the prediction of PPP. This is somewhat surprising, because gender differences were observed in previous studies examining the relationship between social (e.g., cohesion) variables and performance in the sport setting (Carron et al., 2002). Furthermore, gender differences have been observed in various 
other cognitive variables (e.g., spatial abilities; Cahill, 2005). However, it seems that in predicting perceived team performance gender differences were minute. In the current study, the level of the players and teams were relatively similar (i.e., the top 32 teams in the nation) regardless of gender. Thus, it is reasonable to assume that females and males perceived their performance in a similar manner. Future studies should examine the influence of gender on the relationship between PPP and other socio-cognitive factors such as efficacy and leadership.

International status (international/local). In regards to differences between international and local (i.e., American) players, findings suggested that international players perceived their team’s performance at a lower level than local players did. Two possible explanations for these findings are that (a) international players usually come to the USA after playing at higher levels of competition, and (b) international soccer players have higher performance expectations (Popp et al., 2010). Thus, these factors might influence players’ perception of success and may lead to a more realistic or "pessimistic" perception of team performance. Future studies should gather qualitative data using in-depth interviews to gain access to the players' thoughts and understand the rationale for the differences between international and local players. Finally, team-building interventions aimed at converging players' performance expectations (e.g., setting common team goals and norms), as well as at facilitating acculturation experiences of international players, should be implemented by coaches and sport psychologists working in team sport settings.

Class status (freshman/sophomore/junior/senior). Class status was not a significant predictor of PPP. It appears that the number of years playing soccer at the collegiate level may not be associated with perceived performance. Previous studies have shown that the more experienced and skilled athletes are better able to evaluate their own individual performance 
491 (Basevitch et al., 2010). However, college players at this level are close in age and soccer 492 experience, and thus may share a similar understanding of what constitutes optimal and less than 493 optimal performance in team sports. Studies based on the expert-novice paradigm or with a 494 broader target sample (e.g., comparing younger versus older professionals) may elicit potential 495 differences in individuals’ perceptions of team performance.

Starter Status. However, the findings relating to starter status were not significant.

497 Indeed, high-performing teams tend to be less influenced by the formal labeling and status of 498 their members (e.g., starter and substitute, CEO and employee, airline pilot and co-pilot). This so 499 called "leveling effect” is essential to achieve optimal coordination and performance outcomes 500 under time and environmental constraints (Gratton \& Erickson, 2007). It is also possible that the 501 starter role in collegiate soccer does not differentiate among skill levels given that substitutions 502 are unlimited, thus allowing for frequent changes in teams' lineups during official matches (see 503 rules at http://www.naia.org). In addition, all the teams surveyed for the current study qualified 504 to the final tournament, and players were likely to be mentally prepared and aware of their role 505 differences. Furthermore, typically coaches only bring the top 16-18 players to the tournament. 506 This number of players may represent an ideal team size (i.e., not too large, not to small) that 507 aggregates all resources needed for optimal performance. To this extent, size has been found to 508 moderate team performance, with too large or too small teams being associated with poorer 509 collective outcomes (Carron et al., 2007).

Although no differences were found between starts and substitutes, it is important to 511 continue studying the influence of individual rank on expertise development and, perhaps most 512 importantly, on psychological well-being in team sports. Again, previous research has shown 513 that higher ranked athletes show greater perceptions of social cohesion and personal satisfaction 
514 for ability utilization (Jeffery-Tosoni et al., 2011). There are also research on how rule

515 modification may maximize the participation of all team members, particularly in leagues (Hill

516 \& Green, 2008). Overall, advancing knowledge on how to promote psychological well-being

517 among athletes from different skill levels remains a paramount purpose of sport psychology.

518 Laterality. Dominance of left/right leg did not provide any predictive value to the model.

519 Thus, the perception of team performance is not different among left and right-footed soccer

520 players. The players' understanding of their own role (i.e., task-specific knowledge) in relation to

521 the team's overarching goals and coordination dynamics (i.e., team related knowledge) may be

522 more important to performance than laterality by itself. To this extent, Wood and Aggleton

523 (1989) conducted and extensive historical survey on the linkage between laterality and

524 performance ratings among soccer, cricket and tennis players. They found no evidence that left-

525 handed/footed players possess any neurological innate advantage over right-handed/footed

526 players. Thus, the unusually high proportion of left-handed/footed elite athletes is probably due

527 to the fact that right-handers/footers are unaccustomed to face left-handed/footed opponents, thus

528 lacking specific schemas to defend from their strategies and movements.

529

Field positions (goalkeeper/defender/midfielder/offensive). The findings suggest that

530 prediction of PPP is dependent on the player's field position, with exception of midfielders in

531 which no effect was found. In soccer, each position has different objectives and demands (Di

532 Salvo et al., 2007). Thus, perhaps the differences in perceived team performance among the

533 positions stem from the manner in which they evaluate their team performance. For example, if a

534 game ends in a 3-3 tie, offensive players might perceive team performance as a positive

535 outcome, while defenders and goalkeepers will perceive team performance as a negative result, 536 with midfielders perceiving the outcome with mixed feelings. Thus, in adapting this rationale, 
537 the evaluation of team performance is relative to the objectives and demands of the player's field 538 position.

$539 \quad$ Notwithstanding, the lack of predictive power for midfielders may reflect the hybrid 540 characteristics of this position, marked by both defensive and offensive requirements. In fact,

541 midfielders occupy centralized positions, where there is great visibility to teammates and 542 coaches, and the access to information is maximized (Di Salvo et al., 2007). Overall, applied

543 interventions geared at helping players understand and gain knowledge of their teammates’

544 perspective and positional demands should include (a) encouraging players to switch positions

545 during practice, and (b) team discussions on the demands, similarities and idiosyncrasies of each

546 position are warranted.

\section{Team Socio-Cognitive Factors}

548 Cohesion. Perceptions of team social (and not task) cohesion contributed to the

549 predictive value of the model. Noteworthy, in Carron et al.’s (2002) meta-analysis similar results 550 were found, where the relationship was stronger between performance and social cohesion $(d=$ 551 .70) compared to task cohesion $(d=.61)$. Perception of team task cohesion did not differ among 552 teams and individual players probably because all the teams were high-ranked and qualified for 553 the tournament play-offs. Additionally, players were focused on the task and on the preparations 554 for the tournament, which could have also eliminated task differences among teams. Indeed, 555 clear goal and roles are essential to team productivity, and high-performing teams are usually 556 strong about their direction and task assignments (Carron et al., 2007; Eccles \& Tenenbaum, 557 2004). With all high-ranked teams possessing clear tasks and goals, positive affect and a mutual 558 accountability support network may be a better discriminant of team performance. Accordingly, 559 social rather than task related factors may represent a competitive edge, further energizing the 
interactions and performance of top-ranked teams. Of note, these findings mirror research in the business domain in which developing social cohesion is a priority of large companies and world class CEOs (e.g., Google, Nokia). Specifically, transnational companies invest in areas for social interaction within their companies (e.g., workout facilities, restaurants, break areas), as well as numerous socialization and network building practices outside the work environment (e.g., outreach programs, volunteer opportunities) (Gratton \& Erickson, 2007). These efforts collectively aim to foster strong social relationships, developing the mutual trust needed to promote innovation and improve efficiency. Therefore, it is the social aspect that makes critical performance differences when working team members are clear on their task responsibilities.

Team mental models (TMM). Team mental models have only recently been studied in the sport environment (Eccles \& Tran, 2012). Thus, the inclusion of TMM components to explore sport team settings was relatively innovative. Notwithstanding, the lack of predictive power of TMM sub-components (i.e., general task and team knowledge, general task and communication skills, attitudes towards group teammates and task, team dynamics and interactions, and team resources and working environment) does not necessarily mean that performance of elite soccer teams is not linked to TMM. Instead, it is likely that these results reflect a "ceiling-effect” given that expert teams are all characterized by optimal implicit and explicit coordination dynamics. Hence, rather than focus on high-ranked teams only, future studies may (a) consider a different paradigm (expert-novice approach) in comparing bottom to top ranked teams, and (b) accompany the evolution of TMM through developmental approaches and longitudinal growth-models. Future studies should also focus on developing sport specific TMM measurement tools, which may be used to capture and eventually develop intervention programs aimed at improving team performance. 


\section{Conclusions, Limitations and Future Avenues}

This study advanced knowledge on team expertise by assessing both individual and team-

585

586

587

588

589

590

591

592 performance.

593

594

595

596

597

598

599

600

601

602

603

604

605
From a theoretical standpoint, these findings reinforce the importance of testing for the specific effects of task and social cohesion on team performance (Carron et al., 1985; Eys et al., 2007). Individuals from different competitive backgrounds (e.g., recreational, collegiate, professional) may have different social and task attractions to their social groups (Carron et al., 2007). Moreover, these findings corroborate the assumption that members' demographic and role attributes should be accounted for when studying the linkage between team processes (cohesion, TMM) and performance in sports (Carron et al., 2007; Eccles \& Tenenbaum, 2004).

The results of this study are not without limitations. In particular, results are limited in scope, in the sense that not all team-level constructs (e.g., collective-efficacy, leadership, communication) were entered in the HLM model. Results are also limited in terms of generalizability, as our target sample was restricted to high-ranked college soccer teams. The lack of a TMM sport specific measurement tool (at the time of the study) is also noteworthy. The reliance on regression coefficients constitutes an exploratory rather than a confirmatory or 
606 experimental approach, and thus the results presented herein are neither definitive nor causal in 607 nature. Also noteworthy, the low reliability values found for the ATG-T measure were somewhat 608 surprising given the players competed at a high level (i.e., US College), and as such individual 609 perceptions towards the task were expected to be higher. In this regard, it is been proposed that 610 skilled athletes perceive their individual contributions to the team in a highly idiosyncratic 611 manner, and consequently nomothetic psychometric measures may not fully (and reliably) 612 capture their experiences (Hanin, 2007). Future studies should consider using updated 613 psychometric instruments, as well as qualitative methods, in measuring ones’ self-perceptions 614 and meta-cognitive experiences.

615 In view of these limitations, future studies should consider different team-level constructs 616 (e.g., collective-efficacy, leadership) and be grounded in a distinct theoretical orientation (e.g., 617 dynamic systems perspective). Targeting different sub-population groups and developing sport 618 specific measurement tools, as particularly related to TMM, are also avenues for future research. 619 Specifically, sport psychologists should critically analyze which non-sport latent constructs are 620 relevant (i.e., the theoretical and applied concepts, derived from non-sport team building 621 research, relevant to sport and exercise psychologists) and should be operationalized trough the 622 development of sport specific measurement tools (see Brawley \& Paskevitch, 1997). Finally, 623 experimental trials and longitudinal studies are welcomed to identify causal links and the 624 developmental nature of high-performing teams, respectively. 
625

626

627

628

629

630

631

632

633

634

635

636

637

638

639

640

641

642

643

644

645

\section{References}

Basevitch, I., Ward, P., Ericsson, A. K., Ehrlinger, J., \& Medeiros, F. E. (2010). Practice habits, self-beliefs, self-evaluation and soccer skill level. Journal of Sport \& Exercise Psychology, 32, S57-S58.

Brawley, L. R., Carron, A. V., \& Widmeyer, W. N. (1992). The nature of group goals in sport teams: A phenomenological analysis. The Sport Psychologist, 6, 323-333. http://search.proquest.com/docview/618289082?accountid=4840

Cahill, L. (2005, May). His brain, her brain. Scientific American, 292, 40-47.

Carey, D. P., Smith, G., Smith, D. T., Shepherd, J. W., Skriver, J., Ord, L., \& Rutland, A. (2001). Footedness in world soccer: an analysis of France '98. Journal of Sports Sciences, 19, 855-864.

Carless, S. A., \& De Paola, C. (2000). The measurement of cohesion in work teams. Small Group Research, 31, 71-88. doi:10.1177/104649640003100104

Carron, A. V., Brawley, L. R., \& Widmeyer, W. N. (1998). Measurement of cohesion in sport and exercise. In J. L. Duda (Ed.). Advances in sport and exercise psychology measurement (pp. 213-226). Morgantown, WV: Fitness Information Technology.

Carron, A. V., Widmeyer, W. N., \& Brawley, L. R. (1985). The development of an instrument to assess cohesion in sport teams: The group environment questionnaire. Journal of Sport Psychology, 7, 244-266.

Carron, A. V., Colman, M. M., Wheeler, J., \& Stevens, D. (2002). Cohesion and performance in sport: A meta-analysis. Journal of Sport \& Exercise Psychology, 24, 168-188. 
646

647

648

649

650

651

652

653

654

655

656

657

658

659

660

661

662

663

664

665

666

667

Carron, A. V., Eys, M. A., \& Burke, S. M. (2007). Team cohesion: Nature, correlates, and development. In S. Jowette, \& D. Lavallee (Eds.). Social Psychology in Sport (pp.91102). Champaign, IL: Human Kinetics.

Carron, A. V., \& Hausenblas, H. A. (1998) Group dynamics in sport (2nd ed.). Morgantown, WV: Fitness Information technology.

Cooke, N. J., Salas, E., Cannon-Bowers, J., \& Stout, R. J. (2000). Measuring team knowledge. Human Factors, 42, 151-173. doi:10.1518/001872000779656561

Chelladurai, P. (2007). Leadership in Sports. In G. Tenenbaum \& R. C. Eklund (Eds.), Handbook of sport psychology (3rd ed., pp. 113-135). New Jersey: John Wiley \& Sons.

Coleman, J. (2012). A functional model of team leadership for sport. The Florida State University). ProQuest Dissertations and Theses, 136. Retrieved from http://search.proquest.com

Creswell, J. W. (2008). Educational research: Planning, conducting, and evaluating quantitative and qualitative research. Newark, NJ: Pearson.

Di Salvo, V., Baron, R., Tschan, H., Calderon Montero, F. J., Bachl, N., \& Pigozzi, F. (2007). Performance characteristics according to playing position in elite soccer. International journal of sports medicine, 28, 222.

Eccles, D. (2010). The coordination of labour in sports teams. International Review of Sport and Exercise Psychology, 3, 154-170. doi:10.1080/1750984X.2010.519400

Eccles, D. W., \& Tenenbaum, G. (2004). Why an expert team is more than a team of experts: A social-cognitive conceptualization of team coordination and communication in sport. Journal of Sport \& Exercise Psychology, 26, 542-560. 
668 Eccles, D. W., \& Tran, K. B. (2012). Getting them on the same page: Strategies for enhancing

669

670

671

672

673

674

675

676

677

678

679

680

681

682

683

684

685

686

687

688

689

690 coordination and communication in sports teams. Journal of Sport Psychology in Action, 3, 30-40. doi:http://dx.doi.org/10.1080/21520704.2011.649229

Entin, E. E., \& Serfaty, D. (1999). Adaptive team coordination. Human Factors, 41, 312-325. doi:10.1518/001872099779591196

Eys, M. A., Carron, A. V., Bray, S. R., \& Brawley, L. R. (2007). Item wording and internal consistency of a measure of cohesion: The group environment questionnaire. Journal of Sport \& Exercise Psychology, 29, 395-402.

Filho, E. M., Gershgoren, L., Basevitch, I., Schinke, R., \& Tenenbaum, G. (In press). Peer leadership and shared mental models in a college volleyball team: A season long case study. Journal of Clinical Sport Psychology.

Frith, C. (2008). Social cognition. Philosophical Transactions of the Royal Society B, 363, 20332039.

Gratton, L., \& Erickson, T. J. (2007). 8 Ways to Build Collaborative Teams. Harvard Business Review, 85, 100-109.

Hanin, Y. L. (2007). Emotions in sport: Current issues and perspectives. In G. Tenenbaum \& R. Eklund (Eds.), Handbook of sport psychology (3rd ed., pp. 31-58). Hoboken, NJ: Wiley.

Hill, B., \& Green, B. C. (2008) Give the bench the boot! Using Manning Theory to design youthsport programs. Journal of Sport Management, 22, 184-204.

Jeffery-Tosoni, S., Eys, M. A., Schinke, R. J., \& Lewko, J. (2011). Youth sport status and perceptions of satisfaction and cohesion. Journal of Sport Behavior, 34, 150-159.

Johnson, T. E., Lee, Y., Lee, M., OConnor, D. L., Khalil, M. K., \& Huang, X. (2007). Measuring sharedness of team-related knowledge: Design and validation of a shared mental model 
691

692

693

694

695

696

697

698

699

700

701

702

703

704

705

706

707

708

709

710

711

712

instrument. Human Resource Development International, 10, 437-454.

doi:10.1080/13678860701723802

Kamata, A., Tenenbaum, G., \& Hanin, Y. L. (2002). Individual zone of optimal functioning (IZOF): A probabilistic estimation. Journal of Sport \& Exercise Psychology, 24, 189-208.

Katzenbach Mathieu, J. E., Heffner, T. S., Goodwin, G. F., Salas, E., \& Cannon-Bowers, J. (2000). The influence of shared mental models on team process and performance. Journal of Applied Psychology, 85, 273-283. doi:10.1037/0021-9010.85.2.273

Mathieu, J. E., Heffner, T. S., Goodwin, G. F., Salas, E., \& Cannon-Bowers, J. (2000). The influence of shared mental models on team process and performance. Journal of Applied Psychology, 85, 273-283. doi:10.1037/0021-9010.85.2.273

Mohammed, S., Ferzandi, L., \& Hamilton, K. (2010). Metaphor no more: A 15-year review of the team mental model construct. Journal of Management, 36, 876-910. doi:10.1177/0149206309356804

Mullen, B., \& Copper, C. (1994). The relation between group cohesiveness and performance: An integration. Psychological Bulletin, 115, 210-227. doi:10.1037/0033-2909.115.2.210

Popp, N., Hums, M. A., \& Greenwell, T.C. (2010). A comparison of international and domestic student-athletes: Measuring social adjustment and institutional attachment to college. International Journal of Sport Management, 11, 329-346.

Raab, M., \& Johnson, J. G. (2007). Expertise-based differences in search and option generation strategies. Journal of Experimental Psychology: Applied, 13, 158-170.

Raudenbush, S. W., \& Bryk, A.S. (2002). Hierarchical linear models (2nd ed.). Thousand Oaks, CA: Sage Publications. 
713 Salas, E., Rosen, M. A., Burke, C. S., Goodwin, G. F., \& Fiore, S. (2006). The making of a

714

715

716

717

718

719

720

721

722

723

724

725

726

727

728 dream team: When expert teams do best. In K. A. Ericsson, N. Charness, P. J. Feltovich \& R. R. Hoffman (Eds.), The cambridge handbook of expertise and expert performance (pp. 439-453). New York, NY: Cambridge University Press.

Stumpf, S. A., Doh, J. P., \& Tymon, W. (2010). The Strength of HR Practices in India and Their Effects on Employee Career Success, Performance, and Potential. Human Resource Management, 49, 353-375.

Ward, P., \& Eccles, D. W. (2006). A commentary on "team cognition and expert teams: Emerging insights into performance for exceptional teams." International Journal of Sport and Exercise Psychology, 4, 463-483. doi:10.1080/1612197X.2006.9671808

Watt, S. K., \& Moore, J. L. (2001). Who are student athletes? New Directions for Student Services, 93, 7-18.

Widmeyer, W. N., Brawley, L. R., \& Carron, A. V. (1985). The measurement of cohesion in sport teams: The group environment questionnaire. London, CA: Sports Dynamics.

Wood, C. J., \& Aggleton, J. P. (1989). Handedness in fast ball sports: do left-handers have an innate advantage? British Journal of Psychology, 80, 227-240. 
Table 1

Descriptive Statistics and Reliability Estimates for the GEQ and TADM

\begin{tabular}{lcccc}
\hline & \multicolumn{5}{c}{ Descriptive Statistics } \\
\cline { 2 - 5 } Scale & $M$ & SD & Range & Alpha \\
\hline \multirow{2}{*}{ GEQ } & & & & \\
ATG-S & & & & \\
ATG-T $^{\mathrm{b}}$ & 7.29 & 1.45 & $1.2-9$ & .63 \\
GI-S $^{\mathrm{c}}$ & 6.96 & 1.59 & $2-9$ & .56 \\
GI-T $^{\mathrm{d}}$ & 6.71 & 1.25 & $1.25-9$ & .72 \\
Total GEQ $_{\text {TADM }}$ & 6.80 & 1.44 & $2-9$ & .75 \\
GTTK $^{\mathrm{e}}$ & 6.94 & 1.17 & $2.79-9$ & .84 \\
GTC $^{\mathrm{f}}$ & & & & \\
GTT $^{\mathrm{g}}$ & 4.23 & .56 & $2-5$ & .75 \\
TDI $^{\mathrm{h}}$ & 3.84 & .68 & $1.67-5$ & .84 \\
TRWE $^{\mathrm{i}}$ & 4.14 & .63 & $1.33-5$ & .77 \\
Total TADM $_{\text {TOQ }}$ & 3.89 & .65 & $2-5$ & .81 \\
\hline & 3.99 & .64 & $1.33-5$ & .77 \\
& 4.02 & .53 & $2.20-5$ & .93 \\
\hline
\end{tabular}

Note.: ${ }^{\mathrm{a}}$ Individual Attraction to the Group-Social. ${ }^{\mathrm{b}}$ Individual Attraction to the Group-Task. ${ }^{\mathrm{c}}$ Group Integration-Social. ${ }^{\mathrm{d}}$ Group Integration Task. ${ }^{\mathrm{e}}$ General Task and Team Knowledge. ${ }^{\mathrm{f}}$ General Task and Communication. $\quad$ g Attitudes Towards Group Teammates and Task. ${ }^{\mathrm{h}}$ Team Dynamics Interactions. ${ }^{\mathrm{i}}$ Team Resources and Working Environment. 
Table 2

Matrix Correlation among GEQ, TADM and TOQ

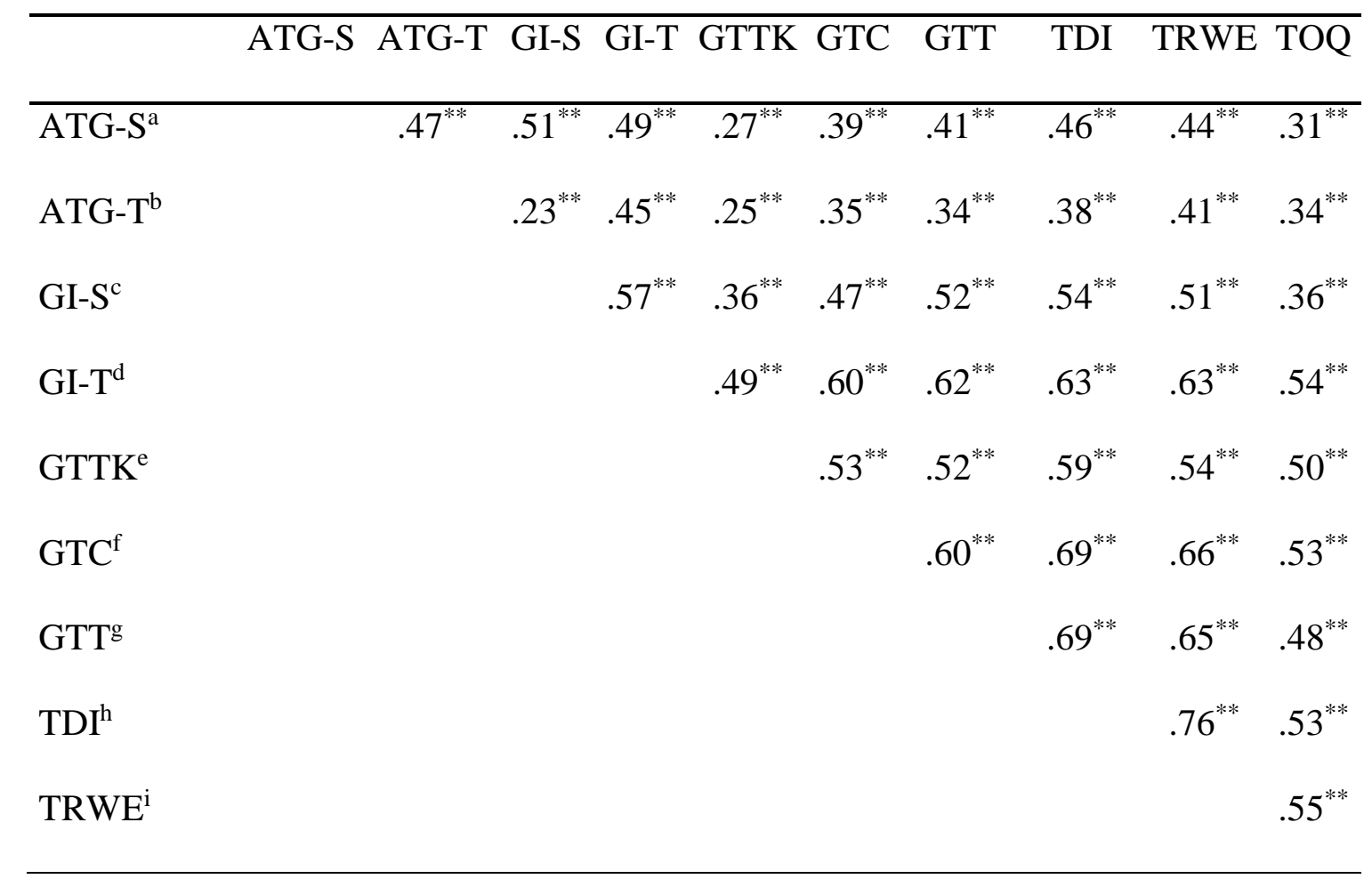

Note.: ${ }^{\mathrm{a}}$ Individual Attraction to the Group-Social. ${ }^{\mathrm{b}}$ Individual Attraction to the Group-Task. ${ }^{\mathrm{c}}$ Group Integration-Social. ${ }^{d}$ Group Integration Task. ${ }^{e}$ General Task and Team Knowledge. ${ }^{f}$ General Task and Communication. $\quad{ }^{\mathrm{g}}$ Attitudes Towards Group Teammates and Task. ${ }^{\mathrm{h}}$ Team Dynamics Interactions. ${ }^{\mathrm{i}}$ Team Resources and Working Environment. 
Table 3

Multilevel Regression Estimates for Model 1A

\begin{tabular}{lcccc}
\hline Fixed Effect & Coefficient & SE & $t$-Ratio & $p$-value \\
\hline Intercept, $\gamma_{00}$ & 67.16 & 10.27 & 6.54 & $<0.01$ \\
Gender, $\gamma_{10}$ & 6.09 & 3.71 & 1.64 & .10 \\
Nationality, $\gamma_{20}$ & -4.17 & 1.77 & -2.35 & .02 \\
Laterality, $\gamma_{30}$ & 0.14 & 1.45 & 0.09 & .92 \\
Starter, $\gamma_{40}$ & -1.67 & 1.35 & -1.24 & .22 \\
Freshman, $\gamma_{50}$ & 4.36 & 8.48 & 0.51 & .61 \\
Sophomore, $\gamma_{60}$ & 6.30 & 8.53 & 0.74 & .46 \\
Junior, $\gamma_{70}$ & 3.38 & 8.47 & 0.40 & .69 \\
Senior, $\gamma_{80}$ & 2.06 & 8.49 & 0.24 & 0.81 \\
Goalkeeper, $\gamma_{90}$ & 11.82 & 5.60 & 2.11 & .04 \\
Defense, $\gamma_{100}$ & 12.53 & 5.40 & 2.32 & .02 \\
Midfielder, $\gamma_{110}$ & 7.39 & 5.37 & 1.38 & 0.17 \\
Offense, $\gamma_{120}$ & 12.56 & 5.42 & 2.32 & .02 \\
Random Effect & Variance & $d f$ & $x^{2}$ & $p$-value \\
Intercept, $u_{0}$ & 49.53 & 16 & 128.79 & $<.01$ \\
Level-1 effect, $r_{i j}$ & 127.02 & & & \\
\hline
\end{tabular}


Table 4

Multilevel Regression Estimates for Model 1B

\begin{tabular}{lccccc}
\hline Fixed Effect & Coefficient & SE & $t$-Ratio & $p$-value & Sig. \\
\hline Intercept, $\gamma_{00}$ & 80.44 & 2.10 & 38.36 & $<.01$ & $* *$ \\
Nationality, $\gamma_{20}$ & -4.09 & 1.709 & -2.40 & .02 & $*$ \\
Goalkeeper, $\gamma_{30}$ & 4.50 & 2.16 & 2.08 & .04 & $*$ \\
Defense, $\gamma_{40}$ & 5.23 & 1.53 & 3.42 & $<.01$ & $* *$ \\
Offense, $\gamma_{50}$ & 5.38 & 1.69 & 3.18 & $<.01$ & $* *$ \\
Random Effect & Variance & $d f$ & $x^{2}$ & $p$-value & $* .01$ \\
Intercept, $u_{0}$ & 50.98 & 16 & 137.77 & & \\
Level-1 effect, $r_{i j}$ & 128.05 & & & & \\
\hline
\end{tabular}

Table 5

Multilevel Regression Estimates for Model 2 (Final)

\begin{tabular}{lcccc}
\hline Fixed Effect & Coefficient & SE & $t$-Ratio & $p$-value \\
\hline Intercept, $\gamma_{00}$ & 54.26 & 8.6564 & 6.23 & $<.01$ \\
GI-S_MEAN, $\gamma_{01}$ & 3.88 & 1.09 & 3.56 & $<.01$ \\
Nationality, 10 & -3.93 & 1.40 & -2.81 & $<.01$ \\
Goalkeeper, $\gamma_{20}$ & 4.61 & 2.38 & 1.93 & .05 \\
Defense, $\gamma_{30}$ & 5.19 & 1.339 & 3.88 & $<.01$ \\
Offense, $\gamma_{40}$ & 5.43 & 1.90 & 2.85 & $<.01$ \\
Random Effect & Variance & $d f$ & $x^{2}$ & $p$-value \\
Intercept, $u_{0}$ & 38.89 & 15 & 97.22 & $<.01$ \\
Level-1 effect, $r_{i j}$ & 128.17 & & & \\
\hline
\end{tabular}




\section{Level-1 Predictors (Individual Characteristics)}

Demographic Factors

- $\operatorname{Gender}(0$ = Female, 1 = Male $)$

- $\operatorname{Nationality~}(0=$ Local Citizen, $1=$ International)

- Class Status

Freshman ( $0=$ No, 1 = Yes $)$

Sophomore $(0=$ No, $1=$ Yes $)$

Junior $(0=$ No, $1=$ Yes $)$

Senior $(0=$ No, $1=$ Yes $)$

$\underline{\text { Soccer Characteristics }}$

- $\quad$ Laterality ( 0 = Left footed, 1 = Right footed $)$

- $\quad$ Starter Status ( 0 = Substitute, 1 = Starter $)$

- Field Position

Goalkeeper $(0=$ No, $1=$ Yes $)$

Defender $(0=$ No, $1=$ Yes $)$

Midfielder $(0=$ No, $1=$ Yes $)$

Offensive player $(0=$ No, $1=$ Yes $)$

\section{Level-2 Predictors (Team Socio-Cognitive Factors)}

\section{$\underline{\text { Cohesion }}$}

- Group Integration Social (GI-S)

- Group Integration Task (GI-T)

Team Mental Models

- General Task and Team Knowledge (GTTK)

- General Task and Communication Skills (GTC)

- Attitudes towards Group Teammates and Task (GTT)

- Team Dynamics and Interactions (GTI)

- Team Resources and Working Environment (TRWE)

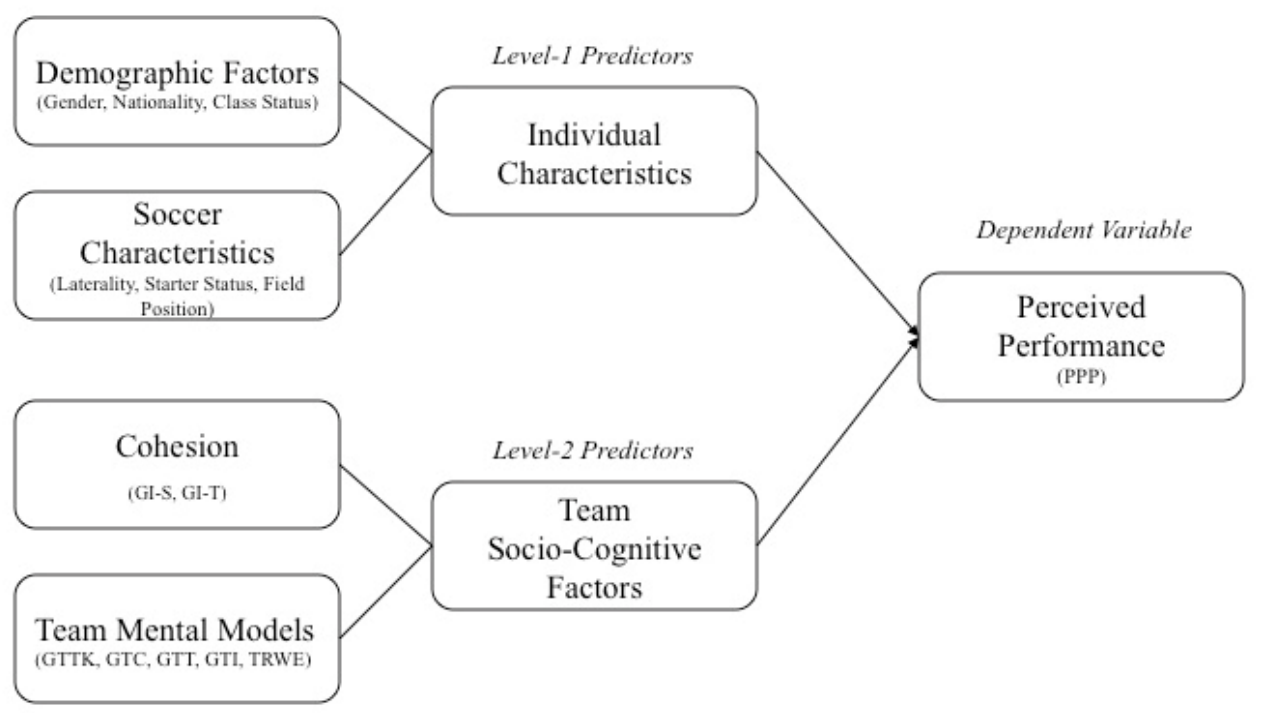

Figure 1. Definition and Representation of the Variable Considered in the Multilevel Equation. 